\title{
Gluten-free Rome
}

\section{Celiac disease in the bioarchaeological record}

\author{
by Rachel Simpson
}

Celiac disease, an autoimmune disorder triggered by consumption of the gluten protein, is theorized to have originated alongside the domestication of wheat during the European Agricultural Revolution, ca. 8000 BCE (Freeman 2013). Human conditions that primarily affect soft tissue, like celiac disease, do not leave tangible evidence on the skeleton and therefore it is difficult to prove their presence. However, recent analyses have employed a suite of macroscopic, molecular, and chemical techniques to establish that a Roman Imperial (100-300 CE) individual from Cosa, Italy, likely suffered from celiac disease. This paper analyzes the works of these researchers and argues that this case study exemplifies modern bioarchaeology, which frequently requires an arsenal of methods beyond visual observation. Using similar syntheses of techniques bioarchaeologists can possibly identify celiac disease in individuals predating $100 \mathrm{CE}$, recreating the origins of celiac disease as well as tackling other previously 'impossible' research questions in this field.

\section{Introduction}

When did celiac disease originate? Scholars have long suggested that the Neolithic Agricultural Revolution in Europe (ca. 8000 BCE) is responsible for a number of diseases and nutritional deficiencies due to agriculture's lack of dietary diversity, implications for social organization and sedentism, and human adaptation (Jönsson et al. 2005, Pinhasi and Stock 2011). A number of digestive diseases linked to the adoption of agriculture, such as celiac disease which afflicts at least $1 \%$ of most human populations, remain a modern issue (Mustalahti et al. 2010; Rubio-Tapia et al. 2012). Researchers suggest that celiac disease originated with the onset of wheat cultivation (Freeman 2013); however, it is difficult to recognize the ailment in the palaeopathological record (Rühli and Ikram

\footnotetext{
Rachel Simpson is a BA (Honours) student in the Department of Anthropology, Economics, and Political Science at MacEwan University (Room 7-368, City Centre Campus, 10700 - 104 Ave., Edmonton, Alberta, T5J4S2 [simpsonr34@mymacewan.ca).
}

2014: 55). Other research has traced the first diagnoses of the ailment to the second century $\mathrm{CE}$ based on the writings of the classical physician Aretaeus the Cappadocian (Losowsky 2008; Freeman 2013). Given that celiac disease is a soft tissue disorder and therefore osteologically absent, there is no way to substantiate these hypotheses.

Italian researchers argue that a skeleton from Roman Imperial (100-300 CE) Tuscany is the first recorded case of archaeological celiac disease. This is due to observable signs of malnutrition in the skeleton, the presence of genetic haplotypes associated with celiac disease, and stable isotope analysis of the remains (Gasbarrini et al. 2010, 2012; Scorrano et al. 2014). This paper will provide a background on both the Neolithic Agricultural Revolution and celiac disease, evaluate the "Case of Cosa," and argue that in encountering archaeologically ambiguous issues, the most valuable approach is a medley of research techniques. 


\section{The Agricultural Revolution}

One of the world's first Agricultural Revolutions took place in approximately 8 000-10 000 BCE in the Levant region of the Middle East, marking the initial shifts from foraging to agriculture with the domestication of cereals (Pinhasi and Stock 2011). Wheat was originally domesticated from a wild einkorn variety approximately $8000 \mathrm{BCE}$ in the Karacadag mountains of modern-day Turkey (Heun et al. 1997). From this epicentre, wheat cultivation spread across the globe. Wheat and alphita (barley with hulls removed) largely constituted the carbohydrate and protein components of the classical Mediterranean diet (Foxhall and Forbes 1982). Currently, it is a part of almost all human diets.

Extensive research exists concerning the impacts of the Neolithic Agricultural Revolution on human life, particularly in terms of changing lifeways (Kelly 1992), social (in)equality (Hayden 1995), and health (Larsen 2006). The adoption of agriculture likely originated through idyllic climatic and social conditions among foragers (Pinhasi and Stock 2011; Bowles and Choi 2015). Bowles and Choi (2015) argue that inferred forager values, such as community sharing practices and collective decision-making, were incompatible with increasing dependence on agriculture, which thrives on individual or nuclear family incentives. Consequently, Bowles and Choi (2015) suggest that the early agricultural transition may have involved increased productivity of land but not necessarily productivity of labour. A shift toward private ownership of land, overall sedentism, and private storage of food surpluses would have slowly developed and led to task specialization and social stratification (Pinhasi and Stock 2011). Additionally, these shifts led to widespread population growth as sedentism supports human fertility and reductions in interbirth intervals (Kelly 1992: 59).
Despite the overall success of sedentary human groups (Wells and Stock 2007), Pinhasi and Stock (2011) argue that there may be a "trade-off" between increased population size and health. Several immediate health implications arose as a result of this transition from foraging to agriculture. Sedentism and overcrowding led to diseases brought about by poor sanitation, as humans increasingly lived in close proximity to their waste and contaminated water (Armelagos et al. 1996; Pinhasi and Stock 2011). The zoonotic transmission of disease also became an issue due to humans living in close quarters with their domesticated animals (Armelagos et al. 1996). There were also several health implications caused by the consumption of domesticated plants themselves. Transitioning from a diverse foraging diet to one that relies on select carbohydrate-rich cereals led to large-scale nutritional deficiencies in specific nutrients (Larsen 2006). Issues with dental health, anemia, and malnutrition are evident in the skeletal record by pathological markers like dental caries (Eshed, Gopher, and Hershkovitz 2006; Larsen 2006), porotic hyperostosis and cribra orbitalia (Papathanasiou, Larsen, and Norr 2000; Stravopodi et al. 2009), and enamel hypoplasia (Krenz-Niedbala 2014) respectively. These studies refute earlier perspectives that agriculture resulted in an overall lifestyle improvement for humans, paving the way for urbanism (Childe 1950).

Many of these direct health implications correspond to recent human evolution as a result of the transition from foraging to agriculture (Pinhasi and Stock 2011). Humans developed lactase persistence and were able to metabolize increased starch quantities, which Jönsson et al. (2005) propose were evolutionary legacies of dietary lectins and leptin resistance. The leptin system is an arrangement of proteins that send signals that inhibit food consumption, facilitate 
the growth of blood vessels, and regulate metabolism and immunity. Lectins are classes of ingested proteins that differ among organisms based on diet. Jönsson et al. (2005) argue that the human leptin system is adapted for certain classes of dietary lectins. Given Homo sapiens' foraging origins, there is a clash between lectins of domesticated cereals and the lectins compatible with the human leptin system. This mismatch of lectins and leptins has led to a rise in certain diseases, including Type 2 Diabetes, obesity, cardiovascular disease, and celiac disease, all which are prevalent in agrarian societies and infrequent in horticultural and foraging societies (Jönsson et al. 2005).

\section{Celiac Disease}

\section{Aetiology}

Celiac disease is a disorder in which an autoimmune response is triggered by the ingestion of gluten, a dietary protein in domesticated wheat (Triticum spp.), barley (Hordeum vulgare), and rye (Secale cereale) (Fasano and Catassi 2001). The only modern treatment for this disease is continual avoidance of gluten in one's diet. By removing the pathogen from a celiac patient's diet, the autoimmune response ceases. Gluten causes the immune system to target the small intestine, leading to inflammation and damage to villi (Holmes, Catassi, and Fasano 2009).

Celiac disease results in malabsorption of nutrients from the small intestine, and it is commonly characterized by symptoms of indigestion, weight loss, diarrhea, and fatigue (Fasano and Catassi 2001; Ransford et al. 2002). In atypical cases, there is also development of steatorrhea; nutritional deficiencies, especially anemia; dermatitis herpetiformis, a glutensensitive skin rash (Reunala 1998); gluten ataxia, a neurological manifestation of gluten sensitivity
(Jackson et al. 2012); and other autoimmune diseases, such as diabetes mellitus (Fasano and Catassi 2001).

The aforementioned symptoms of celiac disease occur in the soft tissues and consequently there are no osteological manifestations of celiac disease. However, some atypical presentations of the disease may have osteological implications. Iron-deficient anemia is a common symptom of celiac disease (Fasano and Catassi 2001; Ransford et al. 2002), which can sometimes be identified on skeletal remains. Additionally, celiac disease has been associated with osteopenia and osteoporosis in some individuals (Valdimarsson et al. 1996), and therefore there is a higher prevalence of bone fractures among patients with celiac disease than among the general population (Vazquez et al. 2000). Children and adolescents with untreated celiac disease may also exhibit a relatively shorter stature due to nutrient malabsorption (Groll et al. 1980). Lastly, 30\% of individuals with long-term untreated celiac disease exhibit enamel hypoplasia (Smith and Miller 1979; Wierink et al. 2007). Therefore, the limited skeletal manifestations of celiac disease may sometimes include porotic hyperostosis, cribra orbitalia, reduced mineral content in bone, reduced bone density, short stature, and/or enamel hypoplasia (Roberts and Manchester 2007: 230; Bianchi and Bardelli 2008). However, it should be noted that these symptoms are not exclusively diagnostic of celiac disease.

\section{Genetic Basis}

Haplotypes are sections of linked genes on a chromosome that are typically inherited together. Celiac disease occurs in individuals with a predisposing human leukocyte antigen system (HLA) haplotype: HLA-DQ2 or HLA-DQ8 (Green and Cellier 2007; Holmes, Catassi, and Fasano 2009). Higher incidences of the HLA-B8 
antigen are also correlated with higher incidences of celiac disease (Cronin and Shanahan 2001). Although $30-35 \%$ of humans exhibit these haplotypes, not all individuals with these haplotypic genetic predispositions will develop celiac disease in their lifetimes (Schuppan,Junker, and Barisani 2009). According to Holmes, Catassi, and Fasano (2009), latent celiac disease can be triggered in genetically-predisposed individuals by large amounts of gluten, infection, and other forms of physiological stress, including pregnancy, puberty, or surgery.

\section{History}

Like obesity, diabetes, and cardiovascular disease, celiac disease is sometimes considered a "disease of affluence" due to its frequency following the Industrial Revolution (Jönsson et al. 2005). However, its rise in frequency during modern times may have more to do with superior methods of diagnosis and greater awareness than its actual origins. Some scholars presume that celiac disease originated sometime after the domestication of wheat (Freeman 2013). According to Freeman (2013), the first diagnosis of celiac disease can be traced back to Aretaeus the Cappadocian, a Greek physician of the second century CE who wrote of an ailment he named "coeliac" that he derived from the Greek word for abdomen, "koiliakos". Aretaeus wrote that "coeliac" involves chronic diarrhea, food indigestion, and abdominal pain; however, these symptoms are not exclusive to celiac disease. Freeman (2013) indicates that "coeliac" may instead be mesothelioma, a cancer of the organ linings. As mesothelioma and celiac disease are diseases of the intestine, both present similar symptoms. Additionally, mesothelioma was 600800 times more common in ancient Cappadocian villages than in the rest of the world (Freeman 2013) due to environmental carcinogens (Selçuk et al. 1992) and the prevalence of an autosomal dominant gene throughout the population (Roushdy-Hammady 2001). Overall, the origins of celiac disease remain uncertain. Celiac disease was officially recognized by physician Samuel Gee, who hypothesized that the "coeliac affection" could potentially be cured by diet (Gee 1888). Finally, in 1950, the dietary connection was revealed; celiac disease was linked to the ingestion of cereals (Dicke 1950).

\section{Prevalence and Distribution}

On average, $1 \%$ of individuals in most modern populations have celiac disease (Mustalahti et al. 2010; Rubio-Tapia et al. 2012). Celiac disease is found across all human populations that regularly consume gluten, which Accomando and Cataldo (2004: 492) refer to as a "global village" of celiac disease. The haplotypes HLA-DQ2 and -DQ8 are not ancestry-specific and there is no patterned distribution of celiac disease. Despite this, there are pockets of higher incidences of celiac disease in Western Ireland, the "celiac belt" of India, Mexico, and Finland (Cronin and Shanahan 2001, Holmes, Catassi, and Fasano 2009, Mustalahti et al. 2010). This variation in the pervasiveness of celiac disease often corresponds to the quantity of wheat consumed in a region. Certain regions of East Asia consume little wheat, and consequently have low frequencies of population-wide celiac disease; in contrast $0.3-2.4 \%$ of European populations that regularly consume glutenous grains have celiac disease (Holmes, Catassi, and Fasano 2009; Mustalahti 2010).

There are some cases in which the incidence of celiac disease does not correspond to gluten consumption. Populations in Ireland exhibit a slightly higher incidence of population-wide celiac disease than near countries like Germany (Cronin and Shanahan 2001). According to Simoons (1981), this can be explained by the spread of wheat cultivation across the globe. Regions with a longer history of wheat cultivation 
have had a longer time to adapt to cereals and humans may micro-evolve to tolerate them. Areas such as Ireland have only recently adopted largescale consumption of wheat, formerly preferring to cultivate oats and potatoes, and therefore do not possess adaptations for metabolizing gluten (Cronin and Shanahan 2001). Without knowing the origin of celiac disease, it is difficult to prove any of these evolutionary hypotheses. Additionally, any conclusions drawn from the distribution of celiac disease should be taken with some reservation, as lack of awareness and/or lack of availability of screening can lead to underdiagnoses of certain conditions (Coresh et al. 2005). Therefore, the currently-known incidence of celiac disease may not reflect the true incidence of celiac disease.

\section{The Case of Cosa}

Although the initial diagnosis of celiac disease is thought to be with Greek physician Aretaeus, celiac disease has never been established from an osteological context. The origins of celiac disease are largely hypothetical, as it does not leave a marked pathology on bone. Despite these limitations, Gasbarrini et al. (2010) hypothesized that a Roman Imperial (100-300 CE) skeleton discovered in Cosa, Italy was a long-term sufferer of celiac disease. In subsequent works (Gasbarrini et al. 2012, Scorrano et al. 2014), a suite of different bioarchaeological methods were employed in order to support this assessment, including morphological and pathological evidence, ancient DNA (aDNA) analysis, and stable isotope analysis.

\section{Celiac Disease Inferred from Pathological Morphology}

In their initial case report, Gasbarrini et al. (2010) suggest that the Roman Imperial individual recovered from the site of Cosa, Tuscany suffered from celiac disease until her death. Age estimates of the Cosa individual suggest that she was in her late teens or early twenties when she died in first century CE. She was buried in a terracotta "alla cappuccina" (gabled tiles) tomb of quality architecture along with grave goods of bronze and gold jewelry. Gasbarrini et al. (2010) infer that the grave goods and the tomb itself suggest that the individual was from a wealthy family of high socioeconomic standing.

Gasbarrini et al. (2010) listed a number of osteological characteristics consistent with undernourishment and anemia. Stature estimations put the individual's height at approximately $140 \mathrm{~cm}$, which is short compared to community data (Giannecchini et al. 2008). The dentition exhibited signs of enamel hypoplasia and reduced overall size of the teeth. Enamel hypoplasia is caused by a slowed secretion of enamel matrix (Roberts and Manchester 2007: 75). The skull exhibits cribra orbitalia, a marker of chronic childhood anemia in which the superior aspect of the eye orbits is porous (Roberts and Manchester 2007: 231). Long bones show a thinning of diaphyseal compact bone. These conditions are often attributed to chronic stress, including but not limited to, undernourishment and anemia. Given that the grave goods and tomb are suggestive of a high socioeconomic status, symptoms of malnourishment are unlikely to reflect a lack of access to food resources and poor socioeconomic conditions. Therefore, Gasbarrini et al. (2010) use the evidence of cribra orbitalia, short stature, and enamel hypoplasia as the sole evidence of undernutrition caused by celiac disease.

While celiac disease could result in these osteological features, cribra orbitalia, stature, and enamel hypoplasia are multifactorial in their aetiology. Iron deficient anemia can be inferred osteologically by porotic hyperostosis, cribra orbitalia, and analysis of iron in bone (Roberts 
and Manchester 2007: 230). Anemia is frequently a symptom of celiac disease as it can result from digestive damage, and by extension, malabsorption of nutrients. Gasbarrini et al. (2010) use this osteological evidence of anemia as primary evidence that the individual had celiac disease. However, anemia is not always caused by diet and is not specific to celiac disease. Genetic hemolytic anemias unrelated to diet (e.g., thalasemia and sickle-cell anemia), enzyme deficiencies, parasitic infections, and abnormal red blood cells can also cause cribra orbitalia and/or porotic hyperostosis (Roberts and Manchester 2007: 232-233; Rothschild 2012). Several other conditions produce symptoms associated with anemia, including but not limited to Crohn's disease (Gasché et al. 1994), chronic kidney disease (McClellan et al. 2004), cancers (Dicato et al. 2010), and menstruation (Milman, Clausen, and Byg 1998).

Similarly, enamel hypoplasia and short stature are not exclusively linked to celiac disease nor do they appear in all cases of celiac disease. Enamel hypoplasia is linked to celiac disease in some patients (Smith and Miller 1979; Wierink et al. 2007) but as a non-specific stress indicator. It is also linked to environmental and societal stressors such as food shortage (Geber 2014), weaning (Ash et al. 2016) and birth weight (Nelson et al. 2013). Enamel hypoplasia can also be a hereditary condition (Robinson, Miller, and Worth1966). Stature is partly inherited from parents but also results from a variety of other intrinsic causes, including hormonal deficiencies in human Growth Hormone (hGH) or thyroid hormones, organ diseases such as Crohn's Disease or cystic fibrosis, genetic syndromes including Turner Syndrome, Noonan Syndrome, and Prader Willi Syndrome (Rogol and Hayden 2014).

In their work, Gasbarrini et al. (2010) neglect to address the possibility of other conditions causing the same pathologies, and do not provide any explanation why celiac disease was their sole conclusion. Inferring celiac disease from nonspecific morphological traits on a poorly preserved skeleton is poor execution of the scientific method regardless of the authors' suggestion for further research on this individual (e.g. stable carbon isotope analysis to reconstruct diet).

\section{Celiac Disease Inferred from Ancient DNA}

Skeletal and dental pathologies alone are insufficient indicators of celiac disease, causing Gasbarrini et al. (2012) to turn to genetic methods for support. The importance of ancient DNA (aDNA) analysis has recently been amplified in bioarchaeological studies, providing answers to questions regarding migration, social organization, family relatedness, origin and evolution of genes, disease, and diet (Stone, 2008). Gasbarrini et al. (2012) postulate that if 99.5\% of celiac disease patients have the same HLA haplotypes, the same predisposition in the Cosa individual would confirm the possibility of celiac disease. Celiac disease and the HLA-DQ2 and -DQ8 haplotypes are not mutually interchangeable, as only $2-5 \%$ of individuals with this haplotypic makeup develop celiac disease (Schuppan, Junker, and Barisani 2009). Gasbarrini et al. (2012) therefore caution that the individual having the genetic predisposition for risk of celiac disease does not definitively 'prove' celiac disease, but it would rule-in the possibility. If she exhibited a disposition other than HLADQ2 or DQ8, it would likely mean that the Cosa individual did not have celiac disease (Gasbarrini et al. 2012).

Based on their aDNA analysis, the Cosa individual was homozygous for the HLA-DQ2 haplotype most common among celiac disease sufferers. The researchers took several precautions to ensure this was an accurate result 
and not contaminated by bacterial, fungal, or researcher DNA. Their analysis (1) extracted aDNA from a number of different locations throughout the skeleton, (2) ran the nuclear DNA and mtDNA of researchers handling the material to cross-check against, and (3) ran multiple independent analyses of the aDNA. Therefore, researcher error is unlikely to have confounded these results. Paired with the morphological observations from Gasbarrini et al. (2010), Gasbarrini et al.'s (2012) aDNA analysis supports the hypothesis that the Cosa individual had celiac disease, and that celiac disease existed by at least the Roman Imperial period. However, the presence of HLA-DQ2 alone does not necessarily mean the individual has celiac disease, as 30$35 \%$ of humans exhibit these same genes. Gasbarrini et al.'s (2012) genetic results do not contradict Gasbarrini et al. (2010) but they also do not prove the hypothesis of celiac disease.

\section{Celiac Disease Inferred from Stable Isotope Analysis}

Scorrano et al. (2014) approached the Cosa case from a different angle, employing stable isotope analysis as a mode of palaeodiet reconstruction. Carbon isotopes analyzed from the organic portion of bone (e.g. collagen) can be used to identify a diet of plants that use a specific photosynthetic pathway, whereas nitrogen isotopes derived from collagen can be used to distinguish diets of different protein sources (Katzenberg 2008). Carbon has two stable isotopes, ${ }^{13} \mathrm{C}$ and ${ }^{12} \mathrm{C}$, which become integrated into plants from atmospheric and oceanic sources via photosynthesis (Schoeninger and Moore 1992). The ratio of the heavier ${ }^{13} \mathrm{C}$ isotope relative to the lighter ${ }^{12} \mathrm{C}$ isotope is represented by the $\delta^{13} \mathrm{C}$ value (Schoeninger and Moore 1992). Terrestrial $\mathrm{C}_{3}$ plants employ three-carbon intermediate molecules in the Calvin-Benson cycle as part of photosynthesis $\left(\mathrm{C}_{3}\right.$ plants are typically crops), while $\mathrm{C}_{4}$ plants employ fourcarbon intermediates $\left(\mathrm{C}_{4}\right.$ plants are typically grasses). $\mathrm{C}_{3}$ and $\mathrm{C}_{4}$ plants also vary in the proportion of ${ }^{13} \mathrm{C}$ taken-up, resulting in distinct ranges of $\delta^{13} \mathrm{C}$ values (Hoefs 2015: 285).Animals of different habitats each have different isotopic signatures based loosely on the available carbon states of local flora (Schoeninger and Moore 1992; Hoefs 2015: 285). Thus, a diet of $\mathrm{C}_{3}$ plants (e.g. wheat and other cultivars) will yield a different carbon isotope ratio compared to a diet of $\mathrm{C}_{4}$ plants (e.g. corn, millet, and wild grasses). Nitrogen isotope analysis is based on the foundation that diets of higher trophic levels have enriched nitrogen relative to lower levels (Katzenberg 2008; Hoefs 2015: 289). As an example, an herbivorous diet will produce a lower nitrogen isotope value than a carnivorous diet. Additionally, diets of freshwater and marine animals are differentiated based on nitrogen isotopes according to trophic level and carbon isotopes because of the presence of dissolved inorganic carbon in marine sources (Katzenberg 2008).

Studies have shown that the Mediterranean diet is mostly characterized by terrestrial, rather than marine and freshwater resources (Craig, Biazzo, and Tafuri 2006). Imperial Rome had a dichotomized diet, with upper and middle class Romans consuming more olives, wine, and wheat, and the poor and enslaved consuming more millet (Killgrove and Tykot 2013). Nevertheless, crossover of all foods existed between groups, and intra-regional variation across the vast Roman Empire existed to a large degree. Isotope studies from throughout Italy have demonstrated the dietary breadth of the Empire. For example, Romans at Velia consumed a higher proportion of cereals (Craig et al. 2009), whereas those at Isola Sacra likely consumed more marine foods than other areas (Prowse et al. 2004) and those at St. Callixtus consumed a 
higher proportion of freshwater resources (Rutgers et al. 2009).

Individual isotopic studies are important, but analyzing one's isotopic values may have little merit without a population baseline. Scorrano et al. (2014) encountered sampling issues in this endeavor as there are no contemporary skeletal populations near Cosa. Alternatively, Scorrano et al. (2014) compared the Cosa individual's results to the Roman isotope studies mentioned above in addition to Cosa (Forum period) samples that date to later periods (sixth century $\mathrm{CE}$ and eleventh to twelfth centuries CE). This was not ideal, as dietary variation occurs across time and space; however, stable isotope analyses of skeletons from these two later time periods revealed carbon and nitrogen values consistent with each other. Faunal remains were also sampled to establish the available local terrestrial and aquatic food web and associated faunal isotopic values (Scorrano et al. 2014).

Results from the stable isotope analysis showed that the Cosa individual had carbon levels similar to the terrestrial animals studied, but with significant differences in nitrogen isotope levels. When compared to data from other Imperial Age Roman sites throughout Italy, the Cosa individual's carbon and nitrogen isotope values also varied. As mentioned above, these contemporary populations from other sources show variation in their consumption of cereals, freshwater, and marine foods. The Cosa individual's isotopic values align closely with those of the St. Callixtus sample, thought to have largely consumed freshwater fish (Rutgers et al. 2009). Roman period Cosa carbon and nitrogen values also varied from later-era Forum skeletons. From these results, Scorrano et al. (2014) suggest that the Cosa individual likely consumed a large proportion of $\mathrm{C}_{3}$ plants or terrestrial $\left(\mathrm{C}_{3}\right.$ plantconsuming animals) whereas later Forum inhabitants consumed more $\mathrm{C}_{4}$ plants. However, these results must be taken with some reservation, due to difficulty in interpreting the meaning of these results without access to isotope levels of the Cosa population contemporary to the individual's time. Furthermore, analysis of stable isotopes from pathological bone can sometimes be distorted (Katzenberg and Lovell 1999). In their analysis, Katzenberg and Lovell (1999) examined pathological evidence of periostitis, fractures, bone atrophy, and osteomyelitis. Their analysis concluded that new bone growth alters the isotopic interpretation, as it records an accelerated period of bone remodelling and consequently, produces higher $\delta^{15} \mathrm{~N}$ levels. Celiac disease has never been researched from an osteological or isotopic perspective, and any resulting effects of the condition on bone could confound this type of research.

In support of a celiac disease diagnosis, Scorrano et al. (2014) propose two explanations for why the Cosa individual had isotope values that were 'outliers' when compared to her home population, why she was isotopically similar to those of the St. Callixtus sample and how these facts might relate to her inferred celiac disease. First, they suggest that the individual began to follow a different diet focused on terrestrial animals or freshwater fish, perhaps after realizing that cereals were an irritant. Avoiding cereals would not have alleviated her illness or cured the intestinal atrophy as gluten must be entirely eliminated from a celiac patient's diet and it is unlikely that she would have been able to remove it completely. Alternatively, Scorrano et al. (2014) propose that intestinal malabsorption of nutrients would have caused the individual to starve. Her body would be forced to metabolize her own muscle tissue for nutrients, leading to higher nitrogen isotope values that appear to show a diet of a higher trophic level similar to a diet of terrestrial animals or freshwater fish. 
Taken on its own, one would not be able to interpret celiac disease from this stable isotope analysis. The Cosa individual's carbon and nitrogen values could have a plethora of implications other than a gastrointestinal disorder. However, in conjunction with the previously published works, this article is valuable in legitimizing the hypothesis of Gasbarrini et al. (2010, 2012). Because the same interpretation could be drawn from all three studies, it is feasible that this individual had celiac disease, making this case the first instance of possible celiac disease from the archaeological record. The collective contribution of macroscopic, molecular, and chemical evidence was essential in substantiating the initial hypothesis of Gasbarrini et al. (2010). Applying this assortment of techniques to future skeletal samples will help to establish earlier cases of celiac disease and pursue concrete evidence of the origins of celiac disease.

\section{Discussion and Conclusions}

The antiquity of celiac disease is an underexplored topic in science, including paleopathology. Due to a lack of historical documentation and diagnostic morphological characteristics on bone, celiac disease can be only officially traced back to its nineteenth century discovery.

This paper summarizes the archaeological evidence for celiac disease in ancient Rome. Taking the works of Gasbarrini et al. (2010, 2012), or Scorrano et al. (2014) on their own provides insufficient evidence of celiac disease. Taken together, however, these morphological, genetic, and isotopic studies present a possible instance of celiac disease in the archaeological record. However, this more holistic interpretation of celiac disease from the Cosa individual is by no means a differential diagnosis.
The morphological osteological evidence presented by Gasbarrini et al. (2010) is not exclusive to celiac disease and could result from numerous other biological and cultural circumstances. Their argument would have been strengthened by considering these other possible causes of the Cosa individual's pathological characteristics. While not detracting from Gasbarrini et al.'s (2010) initial hypothesis, the genetic and stable isotope evidence published by Gasbarrini et al. (2012) and Scorrano et al. (2014) respectively does not conclusively prove the celiac disease hypothesis either. As discussed above, the majority of individuals genetically predisposed to celiac disease do not develop it in their lifetimes. The stable isotope results showed that the Cosa individual under study likely consumed a larger proportion of terrestrial animals and/or freshwater fish; however, there were several limitations to this study, particularly a lack of contemporaneous human samples from Cosa and an absence of any prior research pertaining to the impact of celiac disease on stable isotope analysis.

The results presented in both Gasbarrini et al. (2012) and Scorrano et al. (2014) would have benefitted from comparison to the community data of Cosa. What was the prevalence of the HLA-DQ2 haplotype among the Roman Imperial Cosa population and does it make the genotype of the individual under study more or less significant? Were the individual's carbon and nitrogen isotopic values consistent with other Cosa inhabitants or were the values outliers, and consequently suggestive of an abnormal diet? Unfortunately, no contemporary individuals were excavated in Cosa, making these research questions impossible for the researchers to answer.

Their findings have implications for the scholarly community in terms of celiac disease 
research and paleopathology at the inception of the Agricultural Revolution, as their results demonstrate the possible antiquity of celiac disease, a disorder commonly associated with modern times. There has been a recent "glutenfree boom" (Gaesser and Angedi 2015: 1) resulting from a rise in diagnoses of celiac disease, gluten intolerance, and wheat allergies as well as an emerging popularity of the gluten-free diet among individuals unaffected by the above conditions (2). Given that this subject concerns a large proportion of the general public, research into the origins, past prevalence, and evolution of celiac disease are significant scientific endeavours. While the works of Gasbarrini et al. (2010, 2012) and Scorrano et al. (2014) are encumbered with limitations and cannot be taken as definitive proof of archaeological celiac disease, they present a possible picture of celiac disease and more importantly, they expose a need for future paleopathological research on the affliction.

In conclusion, future bioarchaeological studies in celiac disease should be undertaken. Using new osteological samples and similarly holistic methodologies, while addressing the discussed limitations present in Gasbarrini et al. (2010, 2012) and Scorrano et al. (2014), researchers may be able to attain more conclusive diagnoses of celiac disease. This case study's multifaceted research methodology, while limited in some ways, demonstrates the value in applying a suite of pathological and molecular techniques to bioarchaeological remains. Employing similar approaches may help tackle other 'unanswerable' questions in the future.

\section{References Cited}

Accomando S., and F. Cataldo. 2004. The global village of celiac disease. Digestive and Liver Disease 36(7): 492498.
Armelagos, George J., Barnes, Kathleen C., and James Lin. 1996. Disease in human evolution: The re-emergence of infectious disease in the third epidemiological transition. National Museum of Natural History Bulletin for Teachers 18(3): 1-6.

Ash, Abigail, Michael Francken, Ildikó Pap, Zdeněk Tvrdý, Joachim Wahl, and Ron Pinhasi. 2016. Regional differences in health, diet, and weaning patterns amongst the first Neolithic farmers of central Europe. Scientific Reports 6: 29458.

Bianchi, Maria Luisa, and Maria Teresa Bardella. 2008. Bone in celiac disease. Osteoporosis International 19: 1705-1716.

Bowles, Samuel, and Jung-Kyoo Choi, eds. 2015. The Neolithic Agricultural Revolution. Santa Fe Working Papers: 1-51.

Childe, V. G. 1950. The Urban Revolution. Town Planning Review 21: 3-17.

Coresh, Josef, Danita Byrd-Holt, Brad C. Astor, Josephine P. Briggs, Paul W. Eggers, David A. Lacher, and Thomas H. Hostetter. 2005. Chronic kidney disease awareness, prevalence, and trends among U.S. adults 1999 to 2000. Journal of the American Society of Nephrology 16: 180-188.

Craig, Oliver E., Marco Biazzo, and M. A. Tafuri. 2006. Palaeodietary records of coastal Mediterranean populations. Journal of Mediterranean Studies 16: 6378.

Craig, Oliver E., Marco Biazzo, Tasmin C. O’Connell, Peter Garnsey, Cristina Martinez-Labarga, Roberta Lelli, Loretana Salvadei, Gianna Tartaglia, Alessia Nava, Lorena Renò, Antonella Fiammenghi, Olga Rickards, and Luca Bondioli. 2009. Stable isotopic evidence for diet at the Imperial Roman coastal site of Velia (1st and 2nd centuries AD) in Southern Italy. American Journal of Physical Anthropology 139(4): 572-583.

Cronin, Cornelius C., and Fergus Shanahan. 2001. Why is celiac disease so common in Ireland? Perspectives in Biology and Medicine 44(3): 342-352.

Dicato, M., L. Plawny, and M. Diederich. 2010. Anemia in cancer. Annals of Oncology 21(S7): 167-172.

Dicke, Willem-Karel. 1950. Investigation of the harmful effects of certain types of cereal on patients with coeliac disease. Doctoral dissertation, University of Utretcht.

Eshed, Vered, Avi Gopher, and Israel Hershkovitz. 2006. Tooth wear and dental pathology at the advent of agriculture: New evidence from the Levant. American Journal of Physical Anthropology 130: 145-159.

Fasano, Alessio, and Carlo Catassi. 2001. Current approaches to diagnosis and treatment of celiac disease: An evolving spectrum. Gastroenterology 120(3): 636651.

Foxhall, Lin, and Hamishk A. Forbes. 1982. Sitometreia: The role of grain as a staple food in classical antiquity. Chiron 12: 41-90. 
Freeman, Hugh James. 2013. The Neolithic Revolution and subsequent emergence of the celiac affection. International Journal of Celiac Disease 1(1): 19-22.

Gaesser, Glenn A., and Siddhartha S. Angadi. 2015. Navigating the gluten-free boom. Journal of the American Academy of Physician Assistants 28(8): 1-18.

Gasbarrini, Giovanni, Luca Miele, Gino R. Corazza, and Antonio Gasbarrini. 2010. When was celiac disease born? The Italian case from the archaeological site of Cosa. Journal of Clinical Gastroenterology 44(7): 502503.

Gasbarrini, Giovanni, Olga Rickards, Cristiana MartínezLabarga, Elsa Pacciani, Filberto Chilleri, Lucrezia Laterza, Giuseppe Marangi, Franco Scaldaferri, and Antonio Gasbarrini. 2012. Origin of celiac disease: How old are predisposing haplotypes? World Journal of Gastroenterology 18: 5300-5304.

Gasché, Christoph, Walter Reinisch, Heather Lochs, Babak Parsaei, Sarolta Bakos, Julie Wyatt, G. F. Fueger, and Alfred Gangl. 1994. Anemia in Crohn's disease: Importance of inadequate erythropoietin production and iron deficiency. Digestive Diseases and Sciences 39: 1930-1934.

Geber, Jonny. 2014. Skeletal manifestations of stress in child victims of the Great Irish Famine (1845-1852): Prevalence of enamel hypoplasia, Harris lines, and growth retardation. American Journal of Physical Anthropology 155: 149-161.

Gee, Samuel J. 1888. On the coeliac affection. St. Bartholomew's Hospital Report 24: 17-20.

Giannecchini, Monica, and Jacopo Moggi-Cechi. 2008. Stature in archaeological samples from Central Italy: Methodological issues and diachronic changes. American Journal of Physical Anthropology 135: 284292.

Green, Peter H.R., and Christophe Cellier. 2007. Medical progress: celiac disease. The New England Journal of Medicine 357: 1731-1743.

Groll, A., M. A. Preece, D. C. A. Candy, J. M. Tanner, J. T. Harries. 1980. Short stature as the primary manifestation of coeliac disease. The Lancet 316(8204): 1097-1099.

Hayden, Brian. 1995. Pathways to power: Principles for creating socioeconomic inequalities. In Foundations of social inequality. Douglas Price and Gary M. Fienman, eds. Pp. 15-88. New York: Plenum.

Heun, Manfred, Ralf Schäfer-Pregl, Dieter Klawan, Renato Castagna, Monica Ascerbi, Basilio Borghi, and Francesco Salamini. 1997. Site of einkorn wheat domestication identified by DNA fingerprinting. Science 278: 1312-1314.

Hoefs, Jochen. 2015. Stable Isotope Geochemistry. 7th edition. Switzerland: Springer.

Holmes, Geoffrey, Carlo Catassi, and Alessio Fasano . 2009. Definition and Epidemiology. In Fast facts: Celiac disease. 2nd edition. Abingdon, Oxford: Health Press.
Jackson, Jessica R., William W. Eaton, Nicola G. Cascella, Alessio Fasano, and Deanna L. Kelly. 2012. Neurologic and psychiatric manifestations of celiac disease and gluten sensitivity. Psychiatric Quarterly 83: 91-102.

Jönsson, Tommy, Stefan Olsson, Bo Ahrén, Thorklid C. Bøg-Hansen, Anita Dole, and Staffan Lindberg. 2005. Agrarian diet and diseases of affluence: Do evolutionary novel dietary lectins cause leptin resistance? BMC Endocrine Disorders 5(10): 1-7.

Katzenberg, M. Anne, and Nancy C. Lovell. 1999. Stable isotope variation in pathological bone. International Journal of Osteoarchaeology 9: 316-324.

Katzenberg, M. Anne. 2008. Stable isotope analysis: A tool for studying past diet, demography, and life history. In Biological anthropology of the human skeleton. Katzenberg, M. Anne, and Shelley R. Saunders, eds. 2nd edition. Pp. 413-441. Hoboken, NJ: John Wiley \& Sons.

Kelly, Robert L. 1992. Mobility/sedentism: Concepts, archaeological measures, and effects. Annual Review of Anthropology 21: 43-66.

Killgrove, Kristina, and Robert H. Tykot. 2013. Food for Rome: A stable isotope investigation of diet in the Imperial period (1st-3rd centuries AD). Journal of Anthropological Archaeology 32: 28-38.

Krenz-Niedbala, Marta. 2014. A biocultural perspective on the transition to agriculture in Central Europe. Anthropologie 52(2): 115-132.

Larsen, Clark Spencer. 2006. The agricultural revolution as environmental catastrophe: Implications for health and lifestyle in the Holocene. Quaternary International 150: 12-20.

Losowsky, M.S. 2008. A history of coeliac disease. Digestive Diseases 26: 112-120.

McClellan, William, Stephen L. Aronoff, W. Kline Bolton, Sally Hood, Daniel L. Lorber, K. Linda Tang, Thomas F. Tse, Brian Wasserman, and Marc Leiserowitz. 2004. The prevalence of anemia in patients with chronic kidney disease. Current Medical Research and Opinion 20(9): 1501-1510.

Milman, N., J. Clausen, and K. Byg. 1998. Iron status in 268 Danish women aged 18-30 years: Influence of menstruation, contraceptive method, and iron supplementation. Annals of Hematology 77(1-2): 1319.

Mustalahti, Kirsi, Carlo Catassi, Antti Reunanen, Elisabetta Fabiani, Margit Heier, Stan McMillan, Liam Murray, Marie-Helene Metzger, Maurizio Gasparin, Enzo Bravi, and Markku Mäki. 2010. The prevalence of celiac disease in Europe: Results of a centralized, international mass screening project. Annals of Medicine 42: 587595.

Nelson, Suchitra, Jeffrey A. Albert, Cuiyu Geng, Shelley Curtan, K Lang, S Miadich, M Heima, Anchal Malik, G. Gerretti, Hafsteinn Eggertsson, R. L. Slayton, and Peter Milgrom. 2013. Increased enamel hypoplasia and very low birthweight infants. Journal of Dental Research 92: 788-794. 
Papathanasiou, Anastasia, Clark Spencer Larsen, and Lynette Norr. 2000. Bioarchaeological inferences from a Neolithic ossuary from Alepotrypa Cave, Diros, Greece. International Journal of Osteoarchaeology 10(3): 210-228.

Pinhasi, Ron, and Jay L. Stock, eds. 2011. Human bioarchaeology of the transition to agriculture. Chichester, West Sussex: Wiley-Blackwell.

Prowse, Tracy, Henry P. Schwarcz, Shelley Saunders, Roberto Macchiarelli and Luca Bondioli. 2004. Isotopic paleodiet studies of skeletons from the Imperial Romanage cemetery of Isola Sacra, Rome, Italy. Journal of Archaeological Science 31: 259-272.

Ransford, Rupert A. J., Mark Hayes, Martin Palmer, and Michael J. Hall. 2002. A controlled, prospective screening study of celiac disease presenting as iron deficiency anemia. Journal of Clinical Gastroenterology 35(3): 228-233.

Reunala, Timo. 1998. Dermatitis herpetiformis: Coeliac disease of the skin. Annals of Medicine 30(5): 416-418.

Roberts, Charlotte, and Keith Manchester. 2007. Metabolic and Endocrine Disease. In The archaeology of disease. 3rd edition. Ithaca, NY: Cornell University Press.

Robinson, Geoffrey C., James R. Miller, and H. M. Worth. 1966. Hereditary enamel hypoplasia: Its association with characteristic hair structure. Pediatrics 37(3): 498502.

Rogol, Alan D., and Gregory F. Hayden. 2014. Etiologies and early diagnosis of short stature and growth failure in children and adolescents. The Journal of Pediatrics 164(5): S1-14.

Rothschild, Bruce. 2012. Extirpolation of the mythology that porotic hyperostosis is caused by iron deficiency secondary to dietary shift to maize. Advances in Anthropology 2(3): 157-160.

Roushdy-Hammady, I., J. Siegel, S. Emri, J. R. Testa, and M. Carbone. 2001. Genetic-susceptibility factor and malignant mesothelioma in the Cappadocian region of Turkey. The Lancet 357(9254): 444-445.

Rubio-Tapia, Alberto, Jonas F. Ludvigsson, Tricia L. Brantner, Joseph A. Murray, and James E. Everhart. 2012. The prevalence of celiac disease in the United States. The American Journal of Gastroenterology 107: 1538-1544.

Rühli, Frank J., and Salima Ikram. 2014. Purported medical diagnoses of Pharoah Tutankhamun, c. 1325 BC-. HOMO 65(1): 51-63.

Rutgers, L.V., M. van Strydonck, M. Boudin, and C. van der Linde. 2009. Stable isotope data from the early Christian catacombs of ancient Rome: New insights into the dietary habits of Rome's early Christians. Journal of Archaeological Science 36: 1127-1134.

Schoeninger, Margaret J., and Katherine Moore. 1992. Bone stable isotope studies in archaeology. Journal of World Prehistory 6(2): 247-296.
Scorrano Gabriele, Mauro Brilli, Cristina MartinixLabarga, Francesca Guistini, Elsa Pacciani, Filberto Chilleri, Franco Scaldaferri, Antonio Gasbarrini, Giovanni Gasbarrini, and Olga Rickards. 2014. Palaeodiet reconstruction in a woman with probable celiac disease: A stable isotope analysis of bone remains from the archaeological site of Cosa (Italy). American Journal of Physical Anthropology 154: 349-356.

Schuppan, Detlef, Yvonne Junker, and Donatella Barisani. 2009. Celiac disease: From pathogenesis to novel therapies. Gastroenterology 137: 1912-1933.

Selçuk, Ziya Toros, Lütfi Çöplü, Salih Emri, Ali Fuat Kalyoncu, Ahmet Altay Şahin, Yusuf Izzettin Bariş. 1992. Malignant pleural mesothelioma due to environmental mineral fiber exposure in Turkey: Analysis of 135 cases. Chest 102: 790-796.

Simoons, Frederick J. 1981. Celiac disease as a geographic problem. Food, Nutrition and Evolution. Dwain Newton Walcher and Norman Kretchmer, eds. New York: Mason.

Smith, D. M., and J. Miller. 1979. Gastro-enteritis, coeliac disease and enamel hypoplasia. British Dental Journal 147(4): 91-95.

Stone, Anne C. 2008. DNA analysis of archaeological remains. In Biological anthropology of the human skeleton. M. Anne Katzenberg and Shelley R. Saunders, eds. 2nd edition. Pp. 461-483. Hoboken, NJ: John Wiley \& Sons.

Stravopodi, Eleni, Sotiris K. Manolis, Stravros Kousoulakos, Vassiliki Aleporou, and Michael P. Schultz. 2009. Porotic hyperostosis in Neolithic Greece: New evidence and further implications. Hesperia Supplements 43: 257-270.

Valdimarsson, T., O. Löfman, G. Toss, and M. Ström. 1996. Reversal of osteopenia with diet in adult coeliac disease. Gut 38: 322-327.

Vazquez, Horacio, Roberto Mazure, Diana Gonzalez, Daniel Flores, Silvia, Pedreira, Sonia Niveloni, Edgardo Smecuol, Eduardo Mauriño, and Julio C. Bai. 2000. Risk of fractures in celiac disease patients: A crosssectional, case-control study. American Journal of Gastroenterology 95(1): 183-189.

Wells, Jonathon C.K., and Jay L. Stock. 2007. The biology of the colonizing ape. Yearbook of Physical Anthropology 50: 191-222.

Wierink, Claar D., Denise E. van Dierman, Irene H. A. Aartman, and Hugo S. A. Heymans. 2007. Dental enamel defects in children with coeliac disease. International Journal of Paediatric Dentistry 17(3): 163-168. 